\title{
UNA MIRADA ECLESIOLÓGICA AL DESAFÍO DE LA PLURALIDAD EN LA IGLESIA
}

\author{
An Ecclesiological Perspective on the Challenge of Plurality within Church
}

\author{
Juan Bautista Duhau
}

\section{Resumen}

Los procesos de modernización en América Latina no han impulsado el fin de las religiones como proponían las teorías de la secularización, pero han producido una transformación en los modos de participación y pertenencia caracterizados por la pluralización de grupos y contenidos religiosos. El campo religioso en general se ha pluralizado y diversificado y, al mismo tiempo, se observa una pluralización interna en el catolicismo. La Iglesia católica, a partir del Concilio Vaticano II, reconoce la acción del Espíritu Santo derramando dones y carismas para enriquecer la estructura estable de la comunidad eclesial. La Iglesia se ha transformado internamente al valorar el aporte de renovación y edificación que realizan los carismas personales y comunitarios, las prácticas pastorales novedosas, las nuevas formas de organizarse el laicado y las múltiples agregaciones de fieles son expresión de su diversidad carismática. Estos elementos novedosos responden a las diversas necesidades simbólicas de los fieles católicos y es tarea de la comunidad eclesial acompañar su sana integración y el discernimiento de su valor y validez. Cada momento histórico impulsa procesos de innovación que afectan la estructura estable de la Iglesia y renuevan la tensión entre los elementos novedosos y los elementos institucionales. Ya no solo es una responsabilidad de los dones jerárquicos, sino una tarea sinodal de toda la comunidad eclesial acompañar y discernir si las nuevas experiencias pastorales o nuevas agregaciones de fieles son alternativas válidas o no. El momento presente obliga a incorporar en este discernimiento una particular atención a las posibles desviaciones o derivas sectarias, y el cuidado del desarrollo de ambientes seguros, preventivos de cualquier abuso sexual, de poder o de consciencia.

Palabras clave: Movimiento religioso; Comunidad religiosa; Institución religiosa; Cambio organizacional; Resolución de problemas; Toma de decisiones; Eclesiología; Iglesia Católica.

1 Doctor en Teología por la Pontificia Universidad Católica Argentina. Correo electrónico: jbduhau@outlook.com.ar 


\section{Abstract}

Processes of modernization in Latin America have not accelerated the end of religions, as declared by some proponents of Secularization Theory, but have caused a transformation in the forms of participation and sense of belonging, which are characterized by pluralization of groups and religious contents. In general terms, the religious field has become more plural and diverse; and, at the same time, an internal pluralization of Catholicism has been observed. Beginning with the Second Vatican Council, Catholic Church acknowledges the action of the Holy Spirit, by spreading gifts and charismas to improve the stable structure of the ecclesial community. The Church has transformed herself by recognizing the contribution of renovation and edification of personal and communal charismas, innovative pastoral practices, new forms of organizing laity, and multiple ways of aggregation of believers, all of which are an expression of her charismatic diversity. These new features are the response to the diverse symbolic necessities of Catholic believers, and it is the responsibility of the ecclesial community to accompany a healthy integration and to the judgement about its value and validity. Every historical moment fosters processes of innovation that alter the stable structure of the Church and renovate the tension between innovative and institutional features. Thus, no longer it is the sole responsibility of the hierarchical gifts, but a synodal responsibility of the entire ecclesial community to accompany and judge whether the new pastoral practices and aggregation of believers are valid alternatives. Our time demands a peculiar attention to possible sectarian deviations to this judgment, as well as developing safe environments, which prevent any form of sexual abuse, abuse of power, or abuse of conscience.

Keywords: Religious Movements; Religious Communities; Religious Institution; Organizational Change; Problem Solving; Decision Making; Ecclesiology; Catholic Church.

\section{Introducción}

En este artículo, nos proponemos iniciar una conversación entre los elementos que nos ofrece la sociología de la religión sobre la fragmentación y pluralización del campo católico y la eclesiología posconciliar que ilumina la relación entre los elementos permanentes y estables (institución-ministerio) y los elementos novedosos que irrumpen (carismas) en la Iglesia.

Incorporar la pluralidad como una hermenéutica de la realidad eclesial nos moviliza a vivir una espiritualidad de las tensiones y los conflictos que contiene una sabiduría dialogal. Una mirada positiva sobre la irrupción de lo novedoso en nuestras estructuras pastorales permite valorar la capacidad de renovación que el Espíritu suscita y cuando hay dificultades es capaz de generar senderos de encuentro para colaborar interdisciplinariamente en subsanar las dificultades.

En un primer momento, se describirá la transformación del campo religioso en América Latina en atención a que en esta región no se han dado procesos extremos de secularización provocados por la modernización, como en otras sociedades del planeta. Presentaremos la mutación del campo religioso y su diversificación indicando cómo la disminución del catolicismo se complementa con su pluralización 
interna y con el surgimiento de conflictos entre diversas propuestas de movimientos, comunidades y tendencias católicas de distinta sensibilidad y opción espiritual o religiosa.

En un segundo momento, profundizaremos en la sistemática reflexión pneumatológica y eclesiológica que, surgida a partir del Concilio Vaticano II, permitió reconocer el valor positivo de la acción del Espíritu Santo mediante sus dones en todos los fieles. Este fue el germen para el nacimiento de múltiples experiencias asociativas de fieles en la Iglesia católica. Aún nos encontramos como comunidad eclesial pergeñando los caminos pastorales para la sana integración de esta abundante floración de experiencias pastorales en nuestras diócesis y parroquias. Señalaremos también el valor de evitar los antagonismos entre las dimensiones estables y las realidades dinámicas y novedosas en la Iglesia.

Finalmente, en un tercer momento, describiremos la relación de enmienda recíproca de las dimensiones carismática e institucional en algunos aspectos prácticos, expresados como respuestas extremas o unilateralismos que deben evitarse. Resaltaremos la valiosa posibilidad de asumir una sabiduría dialogal desdramatizadora para asumir las tensiones y los conflictos que permiten integrar las nuevas realidades carismáticas y las recientes propuesta pastorales en las estructuras de la Iglesia local. Concluiremos presentando la urgencia actual de incorporar dos aspectos al discernimiento de la validez de una experiencia pastoral o agregación de fieles: las posibles derivas o desviaciones sectarias y el cuidado de las personas vulnerables frente a la posibilidad de abuso sexual, de poder o de consciencia.

\section{Transformación de la experiencia religiosa en América Latina}

Algunos analistas del fenómeno religioso, durante la segunda mitad del siglo XX, sostuvieron que los procesos de secularización disminuirían radicalmente la influencia social de la religión en el mundo moderno. Con el desarrollo de la modernidad, en su etapa posmoderna o ultramoderna, se produciría el "fin las religiones". Esta visión se sostenía en la experiencia especialmente europea (Morello, 2019); sin embargo, las teorías de la secularización no son leyes sociológicas aplicables directamente a todos los contextos, sino que señalan una tendencia muy variable y heterogénea que debe ser analizada en cada contexto particular (Stolz, 2020).

Es posible distinguir dos caminos divergentes, aunque entrelazados e interrelacionados, entre los procesos de secularización europeos y el crecimiento del pluralismo religioso global. En Europa Occidental, las dinámicas de modernización y urbanización fueron acompañadas de una secularización drástica con un pluralismo religioso limitado. Por el contrario, en gran parte del resto del mundo (América, Asia, el Pacífico y África subsahariana), la modernización y la urbanización han generado un pluralismo religioso con una secularización limitada (Casanova, 2018).

La realidad latinoamericana, caracterizada por la fuerte pervivencia de la religiosidad popular, permitió discutir las hipótesis de la secularización (Parker, 1993, 2019). Si bien los datos varían de acuerdo con los distintos países, es posible observar que en América Latina los procesos de secularización provocados por la modernización no son tan radicales ni directos. En esta región, el campo religioso no ha perdido peso significativo, sin embargo, sufre profundos procesos de cambio; esta transformación de la experiencia religiosa tiene como característica particular que las personas no han dejado de creer en las sociedades modernizadas, pero sí han cambiado sus modos de participación y pertenencia (Lecaros, 2020a). Otro 
de los elementos que permite describir esta mutación del campo religioso es la pluralización de grupos y contenidos religiosos en conjunto con una experiencia religiosa marcada por la incertidumbre y la itinerancia psicológico-espiritual (Mallimaci, 2017; Nizigama, 2020).

El desencantamiento del mundo moderno desestructura simbólicamente las sociedades y los sujetos, pero no significa el fin de las instituciones religiosas. Se favorece una cierta movilidad religiosa, sin que se alcance una desinstitucionalización total; más bien, se produce un cuestionamiento y una transformación, en especial, visible en la ruptura del vínculo directo y estable entre creencias y prácticas. En la modernidad, a pesar del desencanto progresivo, se sostiene la creencia religiosa, aunque con las transformaciones que la caracterizan, tales como el pluralismo, el individualismo y la experiencia privatizada de la creencia (Turco, 2016).

La modernidad ha deshecho ese orden de la tradición en la que institucionalmente se normatizaba cómo creer y cómo expresar lo qué se cree:

Ahora el creer se expresa de manera individualizada, subjetiva, dispersa y se resuelve a través de las múltiples combinaciones y disposiciones de significados, que los individuos elaboran de manera cada vez más independiente del control de las instituciones del creer. (Hervieu-Léger, 2005b, p. 126)

Se produce una diseminación y dispersión de lo religioso que ya no puede ser pensado desde las religiones institucionalizadas, sino que debe ser contemplado desde categorías más amplias, como la creencia o el creer (Hervieu-Léger, 2011).

Las religiones históricas se ven envueltas en un movimiento de reforma global de lo religioso en que conviven muchas paradojas, por ejemplo, se pierde el lenguaje creyente y, simultáneamente, en las nuevas comunidades cristianas crece la búsqueda de expresar emocionalmente la vivencia religiosa subjetiva. De este modo, el cristianismo se fragmenta, se abre un proceso de pluralización y diversificación y se recompone el campo religioso.

Estas transformaciones, principalmente marcadas por la menor influencia del catolicismo y el creciente pluralismo religioso, también suponen una evolución social y política que influye en la gobernabilidad y en el desarrollo del sistema democrático en América Latina (Parker, 2016).

Esta mutación del campo religioso se observa en una disminución progresiva de la hegemonía del catolicismo y su diversificación, en el aumento del protestantismo con un rol público y político, y en el crecimiento de las personas no afiliadas (Esquivel, 2020). La categoría de "no afiliados", que incluye ateos, agnósticos y creyentes sin Iglesia, está creciendo en las sociedades latinoamericanas, sorprendentemente entre las clases bajas. Los latinoamericanos contemporáneos componen su identidad religiosa dentro de una gama más amplia de opciones y de formas específicas en una experiencia de la religiosidad que difumina las fronteras rígidas y produce pertenencias y afiliaciones religiosas fluidas, simultáneas y no exclusivas (Hervieu-Léger, 2005a). Se abre así un abanico de ofertas y se multiplican las alternativas religiosas; a las iglesias pentecostales o evangélicas se suman los nuevos movimientos religiosos ${ }^{2}$ y los cultos afroamericanos.

2 El término nuevos movimientos religiosos (NMR) engloba una gran variedad de fenómenos: desde los cultos y las sectas, que han empezado a competir con las religiones históricas ("grandes Iglesias" o grupos minoritarios antiguos), 
$\mathrm{Al}$ ampliarse el campo religioso, se produce una migración de personas desde el catolicismo hacia otras propuestas; la principal razón de este debilitamiento general del campo católico se debe a la desafiliación y a la propensión de numerosos creyentes a tomar posiciones autónomas y distantes de las normas institucionales (De la Torre, Gutiérrez y Hernández, 2020).

El campo católico se va reduciendo y sufre transformaciones internas: una de sus principalmente mutaciones es su fragmentación y pluralización (Hagopian, 2009). Y si bien se ve reducido en número, continúa siendo mayoritario, y manteniendo aún una fuerte influencia pública, pero viviendo internamente un proceso de diversificación y heterogeneidad "en el que caben opciones doctrinales, políticas, ideológicas y rituales diferenciadas y aún opuestas” (Giménez y Irrazábal, 2010).

Esta pluralización abre una variedad de posibilidades que superan los parámetros dogmáticos establecidos por la institución (Morello et al., 2017). Surgen muchas posibilidades y variedad de opciones dentro del catolicismo, "mostrando agentes, modelos organizativos, situaciones, políticas y modalidades de acción diversas" (Giménez, 2013), de manera que la subjetivación de la creencia permite una diversificación de las formas de ser y representarse de los fieles católicos que participan en los nuevos movimientos eclesiales laicos (De la Torre, 2003). Nos encontramos, entonces, con una diversidad religiosa hacia dentro de una religión, es decir, con un pluralismo interno dentro del campo religioso católico (Giménez y Irrazábal, 2010; Rabbia y Gatica, 2017; Romero, 2009).

En un discernimiento eclesial de la realidad del campo religioso, el Documento de Aparecida va a indicar que las preciosas tradiciones católicas comienzan a erosionarse (Consejo Episcopal Latinoamericano [Celam], 2007, n. 38) y el núcleo profundo de la experiencia religiosa ya no se transmite de una generación a la otra con la misma fluidez (n. 39). Por un lado, numerosas personas pierden el sentido trascendente de sus vidas y abandonan las prácticas religiosas; por otro, un número significativo de católicos transitan hacia otros grupos religiosos (n. 100f) y, concomitantemente, surge un nuevo pluralismo religioso en nuestro continente (n. 100g).

A este panorama debe agregarse que en la experiencia católica comienza a observarse, a partir de las últimas décadas del siglo XX, una fuerte interacción, como intercambio, conflicto y competencia, en el contexto de las diócesis y parroquias entre diversas propuestas de movimientos, comunidades y tendencias católicas de distinta sensibilidad y opción espiritual o religiosa. En el campo religioso latinoamericano, resalta una competencia interinstitucional entre Iglesia y movimiento tanto en sectores populares y progresistas como en medios de extracción social alta y conservadores.

Crece así un pluralismo interno católico y las opciones de pertenencia e identificación se diversifican. Así, por ejemplo, algunas variantes que surgen son una repercusión del fenómeno pentecostal, que muestra a la misma comunidad católica otro modelo pastoral en el campo religioso (Freston, 2012), mientras que en contraste las corrientes disciplinarias ascéticas, compuestas por elementos fundamentalistas o integristas, buscan defender sus posiciones.

hasta los grupos sincréticos de inspiración oriental; desde los movimientos de renovación que se pusieron en marcha dentro de las religiones instituidas, hasta los múltiples componentes de esta "nebulosa místico-esotérica" caracterizados por su capacidad de asimilación y reutilización de todos los saberes disponibles (Hervieu-Léger, 2005b, pp. 60-61). 
Esta experiencia de la pluralidad dentro del campo católico es una experiencia palpable en nuestras diócesis y parroquias, y es también un reto pastoral. Una respuesta a este desafío es integrar la vivencia de lo plural dentro de una comunidad eclesial que se ve a sí misma como "una" Iglesia cuando en realidad es una multiforme diversidad.

La posibilidad de asumir las diversas experiencias pastorales y carismáticas que surgen en las iglesias locales y también universal, sin experimentarlos como un conflicto límite y dramático, supone asumir el criterio de la pluralidad.

La pluralidad es actualmente una hermenéutica, una herramienta para interpretar el fenómeno religioso como se da y como es, y no como deseamos que sea o como pensamos que debe ser. Lo plural ya no es algo que observamos como un objeto de estudio, sino que es una experiencia que proviene de vivir inmersos en la realidad, que siempre ha sido plural, aunque idealmente la proyectamos en trayectorias uniformes o universalizantes (Morra, 2020).

El cambio de época en el cual nos encontramos es radical, y una de sus características fundamentales es la pluralidad generalizada (en la cultura y en la realidad eclesial) ya innegable, y que no debe analizarse solo desde lecturas morales y polares (justo/equivocado, verdadero/falso, etc.) (Morra, 2020). Es necesario asumir que muchas personas al acercarse a nuestras iglesias o espacios pastorales construyen sus universos de sentido en relación con la trascendencia y recorren itinerarios vitales novedosos y poco tradicionales (Lecaros, 2020b).

A partir de este análisis de la realidad eclesial, que nos indica la pluralización y diversificación de la experiencia religiosa, aun dentro de la misma Iglesia católica, en un segundo momento analizaremos el aporte de la eclesiología conciliar que nos ofrece otros criterios teológicos y pastorales para sumar a una nueva hermenéutica de la pluralidad en la Iglesia.

\section{Actualización y renovación de nuestras propuestas pastorales por obra del Espíritu Santo}

El Concilio Vaticano II provocó una reflexión sistemática sobre la acción del Espíritu Santo reconociendo su acción habitual en la vida del creyente. La Iglesia rejuvenece por el poder del Evangelio y el Espíritu continuamente la renueva, edificándola y guiándola "con diversos dones jerárquicos y carismáticos" (Congregación para la Doctrina de la Fe, 2016). ${ }^{3}$

En los textos conciliares, el término carisma es utilizado en catorce oportunidades para señalar que el Espíritu Santo guía a la Iglesia y le provee y gobierna con diversos dones jerárquicos y carismáticos (cf. Concilio Vaticano II, Lumen Gentium, n. 4), distribuye gracias especiales en los bautizados, dones que hacen aptos a los creyentes para construir la Iglesia y que necesitan de un discernimiento apostólico en

3 Las presentes reflexiones forman parte de trabajos del autor sobre la relación orgánica entre la institución y los carismas en la Iglesia-comunión a partir de la perspectiva sobre la Iglesia que propuso el Concilio Vaticano II (Duhau, 2014, 2015). 
su ejercicio (cf. n. 12). La recepción de los carismas genera el derecho y la obligación de ejercitarlos para bien de los hombres y edificación de la Iglesia (cf. Concilio Vaticano II, Apostolicam actuositatem, n. 3), siempre en busca de la unidad y la comunión (cf. Concilio Vaticano II, Ad Gentes, n. 28).

Durante el Concilio se produjo una discusión entre dos modos de comprender cuál es el papel de los carismas en la Iglesia. Estas dos posturas fueron presentadas por el cardenal Ruffini y por el cardenal Suenens. Ruffini representaba un conjunto de padres conciliares que consideraban los carismas como un don extraordinario, milagroso, concedido por Dios en modo excepcional y destinado a confirmar su presencia y su poder. Suenens afirmó que los carismas no son un fenómeno secundario de la vida de la Iglesia, sino que cada cristiano es un receptor de la acción carismática del Espíritu Santo en su vida; en esta concepción, los carismas son dones emparentados con la gracia, que Dios regala habitualmente para el despliegue de la labor evangelizadora de la Iglesia (Pellitero, 1999, 2012; Vanhoye, 2011). Suenes invitó a los padres conciliares a reconocer la existencia de numerosos cristianos que reciben del Espíritu Santo distintos carismas, enriquecedores del ministerio eclesiástico, y propuso que el Concilio describa de modo positivo y constructivo la existencia de los carismas tanto en los pastores como en el pueblo fiel.

Esta visión prevaleció y fue plasmada en Lumen gentium nn. 4 y 12, en que se afirma que estos carismas conceden aptitudes a los fieles, que los hacen diligentes en el desarrollo de las obras y necesidades que presenta la Iglesia, en especial, para construirla y renovarla. Se trata de gracias variadas, algunas extraordinarias, pero otras sencillas y comunes en la comunidad eclesial, adecuadas y útiles para la actividad de la Iglesia (Congregación para la Doctrina de la Fe, 2016, nn. 8 y9).

La enseñanza del Concilio Vaticano II muestra que la obra del Espíritu Santo se realiza a través de sus dones que buscan llenar de vida a los creyentes, hacerlos un pueblo unido y embellecer, rejuvenecer y renovar incesantemente a la Iglesia (Villar, 1998). Más aún, el Espíritu Santo realiza la Iglesia en armonía, no en uniformidad, dado que es principio de unidad y también de distinción y diversidad. Es mediante la comunión y la mutua servicialidad como los dones múltiples y variados en la Iglesia encuentran unidad (Routhier, 2020).

Evidentemente el estilo del discurso adoptado por el Concilio Vaticano II muestra un lenguaje muy positivo que busca resaltar la acción del Espíritu a través de sus carismas, señalando que su aporte de juventud, belleza y renovación debe ser recibido como un descanso y un alivio del que la Iglesia debe estar agradecida. El Concilio resalta el valor de la Iglesia como Pueblo de Dios que marcha en la historia del mundo munida de múltiples carismas y afirma la unidad de la comunidad eclesial realizada por la riqueza de la variedad de sus dones (Congar, 1988, p. 92). Se trata de un estilo discursivo, como clave hermenéutica, que al utilizar términos “como 'carisma', 'diálogo', 'asociación', 'cooperación' y 'amistad' [...] implícitamente abogan por adoptar un nuevo estilo de pensar, de hablar y de comportarse, pasando de un estilo más autoritario y unidireccional a un modelo más recíproco y sensible” (O’Malley, 2012, p. 28).

Queda resaltado en varios pasajes de la doctrina conciliar la libertad del Espíritu Santo que obra según quiere distribuyendo los carismas (cf. Apostolicam actuositatem, n.3; Ad gentes nn. 4 y 23), que son numerosos y diversos (cf. Ad gentes, n. 28), y que se ofrecen para utilidad de la comunidad. 
Esta puesta en práctica de los carismas recibidos debe concretarse en la libertad del Espíritu Santo y siempre en unidad con la comunidad eclesial, en especial, con los pastores "a quienes pertenece el juzgar su genuina naturaleza y su debida aplicación, no por cierto para que apaguen el Espíritu, sino con el fin de que todo lo prueben y retengan lo que es bueno" (Apostolicam actuositatem, n. 3) (Congar, 1991, p. 199). Como señala Vanhoye (1989), "los carismas son situados en una perspectiva de utilidad eclesial, otorgan una aptitud y una disponibilidad para desarrollar diversas actividades útiles a la Iglesia” (p. 299).

Es clara también la enseñanza de Lumen gentium n. 12 que indica que el juicio de la autenticidad y del ejercicio razonable de los carismas es una responsabilidad del ministerio apostólico, al que pertenece la autoridad en la Iglesia para juzgar y "pronunciarse sobre la verdad de tales fenómenos, para que nadie sea víctima del error y que todos se pongan con interés en emplear eficazmente los dones recibidos" (Philips, 1968, p. 225).

A partir de estas expresiones del Concilio, podemos delinear una distinción entre la institución y los carismas, entre los "sacramentos y ministerios" y los "carismas" o "gracias especiales", entre los "dones jerárquicos" y "dones carismáticos". Se trata de una distinción de no oposición, ya que ambos aspectos provienen de un mismo origen, que es el Espíritu Santo, y son dados para la construcción de una misma Iglesia. Y aunque no opuestos sí disímiles, podríamos afirmar que cuentan con un origen y una finalidad común, pero con modos de desplegarse distintivos. Los carismas, como gracias especiales, dependen de la libre iniciativa del Espíritu y no pueden ser controlados o planificados en su surgimiento por la institución. Los dones jerárquicos son universales y comunes, administran ordinariamente la gracia por medio de los ministerios, los sacramentos y el crecimiento en las virtudes.

Por todo esto, resulta muy valioso y vivificador dejar de lado los antagonismos entre las dimensiones estables y las dimensiones que traen novedad y buscar un discurso integrador de ambas, en que se complementan y se necesitan. La Iglesia es institución y carisma, y viceversa, es una estructura viva animada por el Espíritu, que se transforma y responde con la presencia vital del Resucitado a los desafíos cambiantes de los tiempos. Se trata de un dinamismo mutuamente enriquecedor en que la evolución del carisma permite el surgimiento de instituciones que le dan estabilidad y aseguran su supervivencia, y en que las instituciones necesitan el surgimiento de la novedad vital del carisma para evitar los procesos de envejecimiento propios de las mediaciones humanas (Estrada, 1984).

Un elemento que permite relativizar cualquier antagonismo concreto en nuestras comunidades es reconocer el elemento humano inherente a todo carisma y a todo ministerio instituido; se trata de una aceptación de la dimensión humana que se apoya en la dinámica de la Encarnación y en la asunción plena de lo humano por Dios. Tanto los elementos estables instituidos como los elementos renovadores son dimensiones que se hacen concretas en lo humano, ambas pueden ser inspiradas por el Espíritu y ambas necesitan una instancia de discernimiento que permita contrastar con las exigencias evangélicas los procesos de conservación o de transformación que se abren a lo largo del proceso histórico de la comunidad eclesial.

En ambas dimensiones, existe el peligro de querer disponer presuntuosamente del Espíritu Santo tanto en la pluralidad y espontaneidad de los carismáticos como en la textura institucional de la Iglesia, porque, al igual que el servicio de las instituciones, el servicio de los carismáticos es un hacer humano que puede 
degenerar en una obra hecha a medida. Las dos vertientes se necesitan como correctivo eclesial recíproco para resolverse en obediencia al Espíritu Santo (Kehl, 1996).

En este proceso de integración entre carisma y ministerio, la transformación de los modos de participación de los fieles hace necesaria una sana relativización de las estructuras institucionales que permita convertir aquellas formas caducas para que la institución pueda expresar más adecuadamente el espíritu evangélico que le dio origen (Santos, 1967).

Así, por ejemplo, en muchos lugares de la Iglesia, se vive una "petrificación" con una acentuación de la estructura jerárquico-sacramental, expresada en la búsqueda de seguridad y protección por medio de estructuras firmes y una amplia uniformidad en la vida eclesial. Dado que los elementos institucionales son indispensables, es fundamental descubrir cómo actualizarlos. De modo que la acción del Espíritu no solo se manifieste en los carismas personales y comunitarios, sino también en las formas jurídicas e institucionales estables.

Frente a la transformación del campo religioso tanto los elementos estables instituidos (ministerio) como los elementos novedosos (carismas) deben formar gradualmente y en sinergia "entornos sociales comunicativos" con la confianza puesta en la fuerza unificadora del Espíritu Santo. Con el concepto de entornos sociales comunicativos define Kehl (1996) la figura empírica, hoy necesaria, de la Iglesia como "comunión" y como "unidad comunicativa de los creyentes". La Iglesia en la práctica, pastoralmente diríamos en el contexto católico, tiene dos tareas para este teólogo: por un lado, hacer posible expresar la fe en el mundo concreto y cotidiano rescatando la experiencia religiosa de quedar encerrada solo en el sentido festivo de la religiosidad y, por ende, desligada de la vida ordinaria de las personas y los pueblos; y por otro, plasmarse en formas de comunidad que se realicen con vida propia y se comuniquen vitalmente al medio ambiente (Kehl, 1996, p. 180).

Como nos hemos propuesto en este artículo, ha llegado el momento de poner en conversación el elemento sociológico de la pluralidad del fenómeno religioso en la Iglesia católica descripto por los sociólogos de la religión con el elemento eclesiológico del cambio de paradigma y de estilo propuesto por el Concilio Vaticano II.

Dicho lo anterior, no debemos extrańarnos del surgimiento de múltiples experiencias asociativas de fieles en nuestras diócesis y parroquias, ya que la misma Iglesia ha impulsado y propuesto la consciencia de la acción habitual del Espíritu Santo en sus distintos miembros y en la Iglesia misma. Sin embargo, es imprescindible reconocer que el proceso de recepción de esta renovada mirada pneumatológica impacta con fuerzas dispares los distintos ámbitos que componen la comunidad eclesial.

Sin duda, la Iglesia se ha pluralizado internamente, ya el Pueblo de Dios no busca la salvación solo mediante los sacramentos y los misterios, sino también mediante el desarrollo de dones que sean útiles para la renovación y la mayor edificación de la comunidad eclesial. Podríamos sostener que a veces nos sorprendemos del efecto de un proceso que la misma Iglesia católica impulsó en el Concilio. Nos encontramos en plena recepción de esta propuesta del Vaticano II, es decir, estamos buscando recibir un aspecto de la Revelación que hace de la vivencia de la fe con otros un intercambio permanentemente enriquecedor. Se trata de un largo, diversificado y lento proceso de recepción de una novedad propuesta 
por el magisterio eclesial que busca sus caminos prácticos de concreción en la vida de la comunidad eclesial (Polanco, 2013).

En consecuencia, la vida práctica de nuestras comunidades tanto en la diócesis como en las parroquias nos muestra que asumir un nuevo modo de ser Iglesia, no solo a través de los medios instituidos, sino también de nuevos caminos de configurarse la participación y la comunión es complejo, pero no imposible.

En definitiva, los servicios jerárquicos y los dones carismáticos se complementan y a la vez se protegen mutuamente de la deformación de su cometido. Si el ejercicio del ministerio pierde la vitalidad del Espíritu, se ve amenazado por el endurecimiento, más aún por la esterilidad; si el carisma se rebela frente a la autoridad, reinará el desorden y la confusión. Estos son los dos peligros que se desprenden de la doctrina conciliar sobre los carismas, que se vuelve marco de referencia para pensar los cambios pastorales que se suceden con la proliferación de nuevas formas de asociación. En el plano de los carismas, el descontrol que haga perder la unidad a la comunidad eclesial, y en el plano de la institución, una visión demasiado restrictiva de las manifestaciones del Espíritu, que siempre están en el orden del acontecimiento y que llega "de arriba" sorpresivamente.

\section{Tensiones en la Iglesia frente a las propuestas de renovación}

Las prácticas pastorales novedosas, las nuevas formas de organizarse el laicado y las múltiples agregaciones de fieles de muy diverso tenor son expresiones de la fuerza carismática en la Iglesia (Duhau, 2018, 2020). Además, sociológicamente, son la respuesta a un interés religioso, a una demanda ideológica, que se encuentra implícita en las personas que se experimentan convocadas por ese tipo determinado de práctica o de experiencia religiosa. Las experiencias que surgen responden a las diversas necesidades simbólicas de los fieles de todas las vocaciones. Existen intereses religiosos diversos en las personas que aún buscan la experiencia de creer, y las distintas ofertas carismáticas ofrecen alternativas para esa demanda, por lo que será tarea de la comunidad eclesial acompañar y discernir si se trata de alternativas válidas o no (Bourdieu, 2006). ${ }^{4}$

Como hemos señalado, tanto los carismas como las formas institucionales son indispensables para la vida de la comunidad eclesial y conforman una relación de "enmienda recíproca" en que el Espíritu Santo se sirve de la variedad de los carismas (personales y comunitarios) y de las distintas comunidades e Iglesias, para arrancar a la Iglesia de su tendencia a la conservación institucional y conformarla como "sistema abierto", que pasa, de la autosuficiencia carismática de los individuos, comunidades e iglesias, a expandirse en la plenitud "católica" de la fe.

Por el contrario, las estructuras institucionales "utilizadas" por el Espíritu Santo ofrecen la garantía, con su figura objetiva y formalizada, de evitar una autosuficiencia "carismática" (de los individuos o de las comunidades e iglesias) centrada en sí misma y que olvida la unidad superior.

4 El interés religioso se encuentra expresado en la producción, la reproducción, la difusión y el consumo de un tipo determinado de bienes de salvación, que incluye el mensaje religioso mismo (Bourdieu, 1971; Suárez, 2006). 
Al ser la Iglesia una comunidad de carismas y al ser el único Espíritu el que con diversos carismas anima a la Iglesia, aun en el ejercicio del ministerio, se debe afirmar, entonces, que no existe oposición teórica en la reflexión eclesiológica entre carisma e institución, entre espíritu y estructura (De Salis, 2010; Fantappie, 2011). Sin embargo, es necesario distinguir que, frente a cada nueva irrupción carismática, surgen las tensiones y dificultades de orden práctico, que no es decisivo llevar al plano especulativo de la cuestión eclesiológica, sino más bien encontrar caminos de resolución en el plano de las concreciones pastorales (Ratzinger, 1999). En general, tanto los logros como las dificultades en esta tensa relación se observan en la necesidad de concretar una mejor coordinación y mayores mediaciones en el campo pastoral, formativo y de gobierno (Bahíllo, 2018).

Una de las amenazas para la integración de las realidades que presentan alguna novedad en las instancias locales son los unilateralismos, que a lo largo de la historia de la Iglesia han conducido a divisiones, y que, cuando se han sabido resolver, se ha logrado integrar positivamente las novedosas eclosiones.

Tanto en el elemento institucional como en el carismático existen extremos o unilateralismos que son criticables. En el elemento estable de la Iglesia, pueden ser defectos graves la excesiva burocratización y el marcado centralismo, en tanto que en el elemento carismático lo pueden ser las absolutizaciones del propio modo de vivir la fe, debido a ello ambos elementos necesitan un discernimiento que permita evaluar si funcionan al servicio de la comunidad y con vistas a la edificación del Reino de Dios en este mundo, o, si por el contrario, se convierten en elementos que lo dificultan e impiden.

Es inevitable que, en el surgimiento de una nueva experiencia pastoral o una nueva comunidad, la fuerte experiencia inicial de los miembros los lleve a concentrarse sobre sí mismos, en una especie de enamoramiento ingenuo con el riesgo de caer en una absolutización del propio carisma; sin embargo, con el crecimiento y la madurez de las experiencias, sería deseable desprenderse de una autorreferencialidad que asuma la propia experiencia como mejor, más perfecta o predilecta de Dios. El carisma es una modalidad o forma de vivir la experiencia del Evangelio en la Iglesia para una persona y para una comunidad, pero no para todas las personas ni para todos los cristianos. Es deseable que las organizaciones de la Iglesia pueden movilizar entre sus miembros una visión más integrada del propio carisma en la diversidad y pluralidad de caminos de participación y comunión en la comunidad eclesial.

La resolución de este enfrentamiento de unilateralismos es recibir una educación por el Espíritu Santo y por la autoridad eclesiástica suprema en que los carismas y los ministerios deben someterse a las exigencias de esa totalidad que es la Iglesia, sin absolutizar su propio camino, aun cuando en él hayan encontrado la totalidad de la fe y la transmitan; y las iglesias locales y sus obispos no deben obsesionarse por alcanzar una uniformidad de los planes pastorales que ahogue la acción del Espíritu.

En esta mirada, le compete a la dirección apostólica una coordinación de los carismas que no excluye el contraste y las tensiones, por lo que es necesario vivir una espiritualidad de las tensiones y de los conflictos que contiene una sabiduría dialogal desdramatizadora que permite asumir las divergencias sin amargura, con una esperanza activa y un sano sentido del humor (Maccise, 2001).

Por analogía, podemos extrapolar algunas de las recomendaciones para cultivar una adecuada relación entre los movimientos y los obispos locales a todas las iniciativas pastorales que irrumpen en nuestras comunidades. Se propone salir, "primerear", diríamos en palabras de Francisco, al encuentro de lo novedoso 
con caridad, en un impulso que permita conocer adecuadamente su realidad, sin impresiones superficiales o juicios restrictivos. Así, despertar un acompañamiento pastoral cercano, paternal, cordial y sabio, para que se abran caminos reales de integración de las nuevas realidades y puedan ser un aporte generoso, fecundo, también ordenado, a las iglesias particulares; sin olvidar, por eso, la necesidad del discernimiento apostólico para su reconocimiento.

Este servicio de los obispos, en la integración de las nuevas realidades carismáticas, se expresa en acciones tales como conocer, compartir, acoger y acompañar desde una actitud humilde y caritativa para obedecer a la voluntad de Dios, que se manifiesta de modo sorprendente, y así saber orientar coordinando un camino de integración de lo nuevo sin intentar uniformar ni encasillar. La diversificación de la organización eclesial es un signo positivo de una pastoral orgánica en nuestras Iglesias locales (cf. Celam, 2007, n. 99g).

También en la pastoral de las parroquias se debe realizar una tarea de integración de las nuevas realidades eclesiales (movimientos, asociaciones o comunidades), en que el párroco como moderador y dinamizador de la comunión tiene un rol fundamental. Los presbíteros, a quienes el obispo encarga una parte de la Iglesia local, comparten el servicio de acogida de aquel y deben buscar que las parroquias donde llevan adelante su servicio sea una convergencia de vocaciones y carismas; para ello, ejercen su ministerio acompañando, promoviendo y haciendo crecer para beneficio de la comunidad parroquial las vocaciones y los carismas sembrados por el Espíritu Santo (Heredia, 1998; San José Prisco, 2013).

Un crecimiento en la sinodalidad a todo nivel en las Iglesias locales es indispensable para que los conflictos no queden centrados en las personas (obispo-fundador, párroco-dirigente, instancia críticainstancia entusiasta), sino que sea percibido como un servicio de discernimiento y de acompańamiento de la comunidad eclesial en su conjunto a una sana y madura integración (Schickendantz, 2017).

El desarrollo de la sinodalidad supone desarrollar configuraciones pastorales prácticas en que sea posible el discernimiento por "el ejercicio articulado de los variados carismas en una creativa perijoresis eclesial” (Schickendantz, 2017, p. 515). Esto puede ser concretamente analizado en la realización de un sínodo diocesano, pero el crecimiento en la sinodalidad es posible también al nuclearse las diócesis enteras o por sectores en otras estructuras al servicio de la vida sinodal en la Iglesia particular, que algunos autores denominan espacios "parasinodales", como asambleas y congresos (Comisión Teológica Internacional, 2019, p. 52). Otra expresión de la sinodalidad es la constitución de los diversos organismos destinados a coadyuvar en diversas formas el ministerio del obispo en la ordinaria guía pastoral de la diócesis, ámbitos de ejercicio y promoción de la comunión y la sinodalidad, como pueden ser los organismos de comunión y participación previstos por la reforma conciliar: Consejo Presbiteral, Consejo Pastoral Diocesano, Cuerpo de Consultores, Consejo de Asuntos Económicos, etc. (San José Prisco, 2019).

Todas estas instancias pueden hacer su creativo aporte en la tarea sinodal de la comunidad eclesial de acompañar y discernir si las nuevas experiencias pastorales o nuevas agregaciones de fieles son alternativas válidas o no.

Dado que es un terreno complejo la intervención frente a la libertad de asociación de los fieles y la necesidad de ofrecer pautas de funcionamiento sanas a las nuevas realidades, la apertura a la participación y al diálogo en las distintas instancias sinodales pueden ofrecer criterios de discernimiento, acompañamiento e integración de los elementos estables y carismáticos en la comunidad eclesial. 
La lógica dialogal del discernimiento teologal y teológico concretada en las actitudes y los procesos de escucha, diálogo y discernimiento resulta ser un núcleo unificador de la práctica sinodal y las propuestas ya reseńadas de Ratzinger (1999) y Maccise (2001). Se trata de asumir un modo relacional que permite una visión común de las situaciones problemáticas (Galli, 2019). Acercarse a un conflicto entre distintas instancias eclesiales no es muchas veces un conflicto doctrinal dramático, sino una tensión en la vida pastoral concreta que puede ser resuelto en un verdadero encuentro "que crea diá-logos y, por eso, comunicación y comunicación (Comisión Teológica Internacional, 2019, p. 70).

Para terminar, deseamos resaltar dos elementos que la reciente y aún dramática realidad eclesial indica deben ser atendidos prioritariamente y se encuentran imbricados frente al surgimiento de nuevas realidades comunitarias en la Iglesia: las posibles desviaciones o derivas sectarias y la reproducción de ambientes no seguros.

Por un lado, las comunidades y los grupos católicos, como otros grupos no cristianos, pueden caer en la tentación de desviaciones o derivas sectarias, autoritarias o financieras, por la conducción errónea de sus responsables o por una desviación colectiva (Labajos, 2020).

Es factible que ocurran comportamientos disfuncionales en muchos espacios pastorales que en sí mismos no son un problema, sino procederes accidentales ocasionales y temporales. Estos errores pueden ser corregidos con un acompañamiento cercano de los dones jerárquicos o sus delegados; consideramos que sería muy valioso y positivo el aporte interdisciplinario plurivocacional en la ayuda a una realidad eclesial que presenta un momento de crisis o crecimiento para colaborar y subsanar disfunciones.

Algunos episcopados y organizaciones eclesiásticas previenen sobre estas derivas, indicando algunos factores que, detectados en conjunción, hacen necesario un discernimiento más ajustado de la experiencia. ${ }^{5}$ Un solo criterio no es suficiente para calificar negativamente a un grupo o propuesta pastoral, sino que también hay que evitar el abuso de la calificación de secta. Solo un conjunto de criterios combinados permite tomar consciencia de propuestas poco sanas o inmaduras que necesitan el acompañamiento del discernimiento jerárquico y de la comunidad trabajando sinodalmente.

Es conveniente evitar la generalización abusiva o, incluso, la reducción simplista al calificar una experiencia religiosa de sectaria, ya que esto puede ser contraproducente; más bien, se debe buscar identificar las dificultades particulares para ayudar a su corrección (Mine, 2009).

Algunos de estos factores o criterios pueden ser el culto excesivo a la personalidad del fundador, iniciador o líder; los comportamientos negadores de conductas escandalosas por parte de las figuras carismáticas relevantes; la consideración de la propia experiencia religiosa como la única válida, suficiente en sí misma sin referencia a la comunidad eclesial más amplia; la falta de aceptación de las realidades terrenales y, por tanto, de las leyes civiles y religiosas; una experiencia comunitaria muy reducida al propio grupo, aislada del resto de la comunidad eclesial; una insistencia en la ruptura con los vínculos familiares y de amistad para concentrar sus relaciones en la experiencia del grupo o comunidad; la carencia de una formación

5 El episcopado francés ha instaurado una comisión para atender a las desviaciones sectarias en las comunidades católicas (Planet, 2018). 
adecuada; un vocabulario propio; la multiplicación de devociones; unas condiciones de vida inhumanas; una utilización de los bienes bajo el paraguas de la "pobreza" con poca transparencia y justicia; una espiritualidad ascética del sufrimiento con una insistencia en el sacrificio; la manipulación de los miembros en sus diferentes facetas; la confusión del fuero interno y externo, y el autoritarismo de los dirigentes (Conférence des évêques de France, 2019). Por otra parte, las reflexiones realizadas en países que desde el Estado ensayan diversas modalidades de regulación del espacio religioso y buscan ofrecer condiciones de institucionalización son un insumo valioso (Luca, 2003).

En definitiva, la crisis producida por las continuas revelaciones de abusos sexuales es uno de los mayores desafíos que debe enfrentar la Iglesia en el presente y en el futuro. Los problemas desnudados por la crisis de abusos son un signo de los tiempos con los cuales debemos dialogar teológica y pastoralmente (Faggioli, 2019), proponiendo respuestas institucionales de remediación y reforma en la comunidad eclesial (Schickendantz, 2019). En reiteradas ocasiones, la idealización de las figuras carismáticas ha fomentado culturas organizacionales de una "obediencia deferente", en que la persona condesciende al dictamen ajeno, sin querer sostener el suyo (Lennan, 2019).

La crisis de los abusos obliga a reflexionar sobre los estilos de liderazgo en la Iglesia y en las nuevas organizaciones que surjan en su seno, asumiendo el nuevo paradigma de abuso sexual, que no mira solo la edad de la víctima, sino también las asimetrías de poder que producen un vínculo abusivo y vulneran la dignidad de la persona (Béraud, 2019; Murillo, 2020).

\section{Conclusiones}

La fragmentación de la experiencia religiosa es constatable y supone un proceso abierto de pluralización, diversificación y recomposición del campo religioso también en la Iglesia católica. Frente a esta pluralidad que nos desafía, es posible acrecentar nuestra consciencia eclesial valorando la presencia renovadora del Espíritu Santo en la continuidad de la acción evangelizadora de la Iglesia, por medio de los diversos dones jerárquicos y carismáticos.

El Espíritu Santo es principio activo interior, garantía de novedad y continuidad en una comunidad eclesial viva, y su fuerza es capaz de actualizar aquello original para que no sea "viejo" sino "nuevo" para la realidad nueva en la historia que transcurre. Su dynamis es capaz de poner en comunión para los hombres el tiempo de la historia salvífica y el tiempo de la Iglesia.

Tanto los dones jerárquicos en su función de discernir y guiar como los diversos dones carismáticos deben invocar la asistencia de este Espíritu frente a los procesos de renovación que enfrentan las diversas realidades eclesiales.

Francisco (2013), en su exhortación apostólica Evangelii gaudium, señala la necesidad de un cambio de estructuras y presenta la necesidad de dejar atrás una actitud simplemente administrativa de la Iglesia. Convertir la visión burocrática de la misión eclesial es dar pasos para renovar el dinamismo evangelizador de la Iglesia, identificar aquellas estructuras que lo puedan condicionar y llenar de vida las buenas 
organizaciones. Así, la Iglesia está llamada a revisar aquellas costumbres propias, arraigadas a lo largo de la historia, que están no directamente ligadas al núcleo del Evangelio, y que en el presente no prestan el mismo servicio en orden a su transmisión.

Es imprescindible distinguir entre aquello sustancial, permanente y necesario a la vida, y la esencia de la Iglesia, de aquello contingente, que cambia, porque la Iglesia está inmersa en la historia. En esta tarea de renovación, los carismas son regalos del Espíritu integrados en el cuerpo eclesial para renovar y edificar la Iglesia, los cuales expresan su fecundidad al integrarse armónicamente en la vida de la Iglesia, sin arrojar sombras sobre otras espiritualidades y dones para afirmarse a sí misma. Para esta integración, es necesario asumir en la Iglesia la obra del Espíritu Santo, que no solo suscita la diversidad, pluralidad y multiplicidad de carismas, vocaciones y servicios, sino que también los reúne en una actitud de comunión, muy distinta de una actitud de uniformidad u homologación.

\section{Referencias}

Bahíllo Ruiz, T. (2018). Las relaciones entre obispos y religiosos en la Iglesia: realidad y perspectivas a los XXX años del Mutuae relationes. Estudios Eclesiásticos, 83(327), 547-573. Recuperado de https://revistas.comillas.edu/ index.php/estudioseclesiasticos/article/view/861

Béraud, C. (2019). Ce que la publicisation des scandales sexuels fait au catholicisme français. Archives de sciences sociales des religions, 4(188), 131-140. https://doi.org/10.4000/assr.46746

Bourdieu, P. (1971). Genèse et structure du champ religieux. Revue française de sociologie, 13(2), 295-334. https:// doi.org/10.2307/3320234

Bourdieu, P. (2006). Génesis y estructura del campo religioso. Relaciones: Estudios de Historia y Sociedad, 27(108), 29-83. Recuperado de https://www.redalyc.org/articulo.oa?id=137/13710803

Cardona Ramírez, H. \& Ángel, M. (2017). La impronta bíblica de laudato si'. Diálogo a dos voces entre la encíclica y los inicios del génesis. Cuestiones Teológicas 44, (102), 301-346. https://doi.org/10.18566/cueteo.v44n102.a05

Casanova, J. (2018). The Karel Dobbelaere lecture: Divergent global roads to secularization and religious pluralism. Social Compass, 65(2), 187-198. https://doi.org/10.1177/0037768618767961

Comisión Teológica Internacional. (2019). La sinodalidad en la vida y en la misión de la Iglesia. En S. Madrigal Terrazas (Ed.), La sinodalidad en la vida y en la misión de la Iglesia: texto y comentario del documento de la Comisión Teológica Internaciones (pp. 3-77). Madrid: Biblioteca de Autores Cristianos.

Conférence des évêques de France. (2019). Dossier de presse: Dérives sectaires dans des communautés catholiques. Recuperado de https://eglise.catholique.fr/espace-presse/dossiers-de-presse/481828-derives-sectairescommunautes-catholiques/

Congar, Y. M.-J. (1988). Llamados a la vida. Barcelona: Herder.

Congar, Y. M.-J. (1991). El Espiritu Santo. Barcelona: Herder.

Concilio Vaticano II. (1964). Constitución Dogmática Lumen Gentium. Noviembre 21 de 1964. http://bit.ly/3r4lkVA 
Concilio Vaticano II. (1965). Decreto Apostolicam Actuositatem. Noviembre 18 de 1965. http://bit.ly/38UCdMg

Concilio Vaticano II. (1965). Decreto Ad Gentes. Diciembre 7 de 1965.

http://www.vatican.va/archive/hist_councils/ii_vatican_council/documents/vat-ii_decree_19651207_ad-gentes_ sp.html

Congregación para la Doctrina de la Fe. (2016). Carta Iuvenescit ecclesia a los obispos de la Iglesia católica sobre la relación entre los dones jerárquicos y carismáticos para la vida y misión de la Iglesia. Mayo 15 de 2016. http://bit.ly/3vCezxH

Consejo Episcopal Latinoamericano. (2007). V Conferencia General del Episcopado Latinoamericano y del Caribe, Documento de Aparecida. Buenos Aires: Oficina del Libro Conferencia Episcopal Argentina.

De la Torre, R. (2003). La diversidad católica vista desde los nuevos rostros de Dios. Ciencias Sociales y Religión, 5(5), 11-36. https://doi.org/10.22456/1982-2650.2252

De la Torre, R., Gutiérrez, C. y Hernández, A. (2020). Religious reconfiguration in Mexico: Beliefs and Practices National Survey, 2016. Social Compass, 67(3), 349-371. https://doi.org/10.1177/0037768620922122

Duhau, J. B. (2014). La relación orgánica entre la institución y los carismas en la Iglesia-comunión (Tesis de grado). Recuperado de https://repositorio.uca.edu.ar/handle/123456789/547

Duhau, J. B. (2015). La relación entre la institución y los carismas en cuatro autores europeos contemporáneos. Teología, 52(118), 67-84. Recuperado de https://erevistas.uca.edu.ar/index.php/TEO/article/view/1193

Duhau, J. B. (2018). Carisma e institución en las nuevas realidades carismáticas: crecimiento y crisis en los movimientos eclesiales y nuevas comunidades. Teología, 55(127), 189-212. Recuperado de http://erevistas.uca.edu.ar/ index.php/TEO/article/view/1673

Duhau, J. B. (2020). "Otras salidas": alternativas de los miembros leales frente al deterioro de las nuevas realidades carismáticas. Cuestiones Teológicas, 47(107), 106-122. https://doi.org/10.18566/cueteo.v47n107.a07

Esquivel, J. C. (2020). As contribuiçôes e dilemas dos estudos quantitativos nas ciências sociais da religião na América Latina. Ciencias Sociales y Religión, 22. Recuperado de https://econtents.bc.unicamp.br/inpec/index.php/csr/ article/view/13449

Estrada Díaz, J. A. (1984). La Iglesia: ¿institución o carisma? Salamanca: Sígueme.

Faggioli, M. (2019). The catholic sexual abuse crisis as a theological crisis: Emerging issues. Theological Studies, 80(3), 572-589. https://doi.org/10.1177/0040563919856610

Fantappie, C. (2011). Spirito e Istituzione: la prospettiva teologico-canonistica. En Politica e religione: Annuario di teologia politica (pp. 57-94). Brescia: Morcelliana.

Francisco. (2013). Exhortación Apostólica Evangelii Gaudium. Noviembre 24 de 2013. http://www.vatican.va/content/ francesco/es/apost_exhortations/documents/papa-francesco_esortazione-ap_20131124_evangelii-gaudium. html

Freston, P. (2012). Las dos transiciones futuras: católicos, protestantes y sociedad en América Latina. En C. Parcker (Ed.), Religión, politica y cultura en América Latina: nuevas miradas (pp. 77-97). Santiago de Chile: Universidad de Santiago de Chile.

Galli, C. M. (2019). Iglesia sinodal y sinodalidad de la Iglesia: fundamentos teologales y teológicos. En En S. Madrigal Terrazas (Ed.), La sinodalidad en la vida y en la misión de la Iglesia: texto y comentario del documento de la Comisión Teológica Internaciones (pp. 81-109). Madrid: Biblioteca de Autores Cristianos. 
Giménez Béliveau, V. (2013). En los márgenes de la institución: reflexiones sobre las maneras diversas de ser y dejar de ser católico. Corpus: Archivos Virtuales de la Alteridad Americana, 3(2). https://doi.org/10.4000/ corpusarchivos. 585

Giménez Béliveau, V. y Irrazábal, G. (2010). Católicos en Argentina: hacia una interpretación de su diversidad. Sociedad y Religión, 32, 42-59. Recuperado de https://www.aacademica.org/gabriela.irrazabal/61

Hagopian, F. (2009). Introduction: The new landscape. En F. Hagopian (Ed.), Religious pluralism, democracy, and the Catholic Church in Latin America (pp. 1-64). Notre Dame: University of Notre Dame Press. https://doi. org/10.2307/j.ctvpj78r9.7

Heredia, C. (1998). La parroquia: convergencia de vocaciones y carismas. En J. Bonet Alcón (Ed.), Pastores y fieles: constructores de la comunidad parroquial (pp. 67-87). Buenos Aires: Educa.

Hervieu-Léger, D. (2005a). Bricolage vaut-il dissémination? Quelques réflexions sur l'opérationnalité sociologique d'une métaphore problématique. Social Compass, 52(3), 295-308. https://doi.org/10.1177/0037768605058427

Hervieu-Léger, D. (2005b). La religión, hilo de memoria. Barcelona: Herder.

Hervieu-Léger, D. (2011). Faut-il définir la religion? Questions préalables à la construction d'une sociologie de la modernité religieuse. Archives de sciences sociales des religions, 63(1), 11-30. Recuperado de http://journals. openedition.org/assr/23034

Hervieu-Léger, D. (2012). Algunas paradojas de la modernidad religiosa. Versión: Estudios de Comunicación y Política, 21, 15-29. Recuperado de https://versionojs.xoc.uam.mx/index.php/version/article/view/326/325

Kehl, M. (1996). La Iglesia: eclesiología católica. Salamanca: Sígueme.

Labajos, A. (2020). Abusos de poder y de consciencia en la vida consagrada. Vida Nueva, 3191, 23-30. https://www. vidanuevadigital.com/pliego/abusos-de-poder-y-de-consciencia-en-la-vida-consagrada/

Lecaros, V. (2020a). L'existence de Dieu, une évidence en Amérique Latine? Theologica Xaveriana, 70. https://doi. org/10.11144/javeriana.tx70.ldeal

Lecaros, V. (2020b). Les oxymores religieux latino américains: étude sur l'enchantement et les processus de sécularisation au Pérou. Social Compass, 67(3), 444-460. https://doi.org/10.1177/0037768620922935

Lennan, R. (2019). Beyond scandal and shame: Ecclesiology and the longing for a transformed church. Theological Studies, 80(3), 590-610. https://doi.org/10.1177/0040563919856370

Luca, N. (2003). De la régulation étatique du religieux. Archives de sciences sociales des religions, 122, 31-37. https:// doi.org/10.4000/assr.1503

Maccise, C. (2001). Intervención del prepósito general de la Orden de los Carmelitas Descalzos, en la Segunda Congregación General del lunes 1 de octubre de 2001 del X Sínodo de los Obispos sobre el tema "El obispo servidor del Evangelio de Jesucristo para la esperanza del mundo". Recuperado de https://bit.ly/3aXwl4z

Mallimaci, F. (2017). Modernidades religiosas latinoamericanas: un renovado debate epistemológico y conceptual. Caravelle: Cahiers du monde hispanique et luso-brésilien, 108, 15-33. https://doi.org/10.4000/caravelle.2218

Mine, B. (2009). La notion de "dérive sectaire": quelle(s) implication(s) pour la régulation du "phénomène sectaire"? Champ pénal/Penal field, 6. https://doi.org/10.4000/champpenal.7535

Morello, G. (2019). Why study religion from a Latin American sociological perspective? An introduction religions issue, "Religion in Latin America, and among Latinos abroad". Religions, 10(6), 399. http://dx.doi. org/10.3390/rel10060399 
Morello, G., Romero, C., Rabbia, H. y Da Costa, N. (2017). An enchanted modernity: Making sense of Latin America’s religious landscape. Critical Research on Religion, 5(3), 308-326. https://doi.org/10.1177/2050303217732131

Morra, S. (2020). ¿ Yo soy el otro? El cristianismo de frente a los nuevos desafíos de la pluralidad. En “... en nuestras propias lenguas las maravillas de Dios.” (Hech 2,11) Iglesia(s) - Sociedad(es) - Cultura(s) (pp. 25-44). Buenos Aires: Sociedad Argentina de Teología.

Murillo, J. A. (2020). Abuso sexual, de consciencia y de poder: hacia una nueva definición. Estudios Eclesiásticos, 95(373), 415-440. https://doi.org/10.14422/ee.v95.i373.y2020.005

Nizigama, I. (2020). Saisir le "nouveau pluralisme religieux": l'approche de Peter L. Berger. Studies in Religion/Sciences Religieuses, 49(1), 109-136. https://doi.org/10.1177/0008429819844496

O’Malley, J. W. (2012). ¿Qué pasó en el Vaticano II? Santander: Sal Terrae.

Parker, C. (1993). Otra lógica en América Latina: religión popular y modernización capitalista. México: Fondo de Cultura Económica.

Parker, C. (2016). Religious pluralism and new political identities in Latin America. Latin American Perspectives, 43(3), 15-30. https://doi.org/10.1177/0094582x15623771

Parker, C. (2019). Popular religions and multiple modernities: A framework for understanding current religious transformations. Religions, 10(565). http://dx.doi.org/10.3390/rel10100565

Pellitero, R. (1999). El Espíritu Santo y la misión de los cristianos: los carismas, unidad y diversidad. En P. Rodríguez, J. R. Villar Saldaña y R. Pellitero (Eds.), El Espiritu Santo y la Iglesia: XIX Simposio Internacional de Teología de la Universidad de Navarra, Pamplona (pp. 505-540). Pamplona: Universidad de Navarra.

Pellitero, R. (2012). Carisma. En J. Otaduy, A. Viana y J. Sedano (Eds.), Diccionario general de derecho canónico (vol. 1, pp. 873-877). Pamplona: Thomson Reuters Aranzadi.

Philips, G. (1968). La Iglesia y su misterio en el Concilio Vaticano II: historia, texto y comentario de la constitución Lumen gentium (vol. 1). Barcelona: Herder.

Planet, A. (2018). Dérives sectaires dans des communautés catholiques. París: Conférence des évêques de France.

Polanco, R. (2013). Concepto teológico de recepción con vistas a su aplicación al desarrollo posterior al Concilio Vaticano II. Teologia y Vida, 54(2), 205-231. http://dx.doi.org/10.4067/S0049-34492013000200002

Rabbia, H. H. y Gatica, L. (2017). Being a Roman Catholic in a context of religious diversity: An exploration of lived religion among Catholics in Córdoba, Argentina. Visioni LatinoAmericane, 9(17), 38-64. Recuperado de https://www.openstarts.units.it/handle/10077/18470

Ratzinger, J. (1999). Los movimientos eclesiales y su lugar teológico. Communio, 20, 87-108. http://repositorio. ugm.cl/handle/20.500.12743/1017

Romero, C. (2009). Religion and public spaces: Catholicism and civil society in Peru. En F. Hagopian (Ed.), Religious pluralism, democracy, and the Catholic Church in Latin America (pp. 365-402). Notre Dame: University of Notre Dame Press. https://doi.org/10.2307/j.ctvpj78r9.15

Routhier, G. (2020). La pneumatologie de Vatican II. Perspectiva Teológica, 52(2), 375-392. https://doi.org/10.20 $911 / 21768757 \mathrm{v} 52 \mathrm{n} 2 \mathrm{p} 375 / 2020$

Salis Amaral, M. D. (2010). Lo Spirito Santo e la Chiesa: risposte di Congar e del Vaticano II al problema "carisma e istituzione". Pontificia Accademia di Teologia, 9(2), 364-382. https://ixtheo.de/Record/1647041902 
San José Prisco, J. (2013). Un párroco renovado para una parroquia evangelizadora. Vida Nueva, 2836, 23-30. https:// www.vidanuevadigital.com/pliego/un-parroco-renovado-parauna-parroquia-evangelizadora/

San José Prisco, J. (2019). Las estructuras de la sinodalidad en la Iglesia local: consideraciones canónicas. En S. Madrigal Terrazas (Ed.), La sinodalidad en la vida y en la misión de la Iglesia: texto y comentario del documento de la Comisión Teológica Internaciones (pp. 141-174). Madrid: Biblioteca de Autores Cristianos.

Santos Díez, J. L. (1967). Jerarquía y carisma en el gobierno de la Iglesia. Ius Canonicum, 7(14), 321-363. Recuperado de https://revistas.unav.edu/index.php/ius-canonicum/article/view/22279/18509

Schickendantz, C. (2017). La reforma de la Iglesia en clave sinodal: una agenda compleja y articulada. Teología y Vida, 58(1), 35-60. http://dx.doi.org/10.4067/S0049-34492017000100002

Schickendantz, C. (2019). Fracaso institucional de un modelo teológico-cultural de Iglesia: factores sistémicos en la crisis de los abusos. Teología y Vida, 60(1), 9-40. http://dx.doi.org/10.4067/S0049-34492019000100009

Stolz, J. (2020). Secularization theories in the twenty-first century: Ideas, evidence, and problems. Presidential address. Social Compass, 67(2), 282-308. https://doi.org/10.1177/0037768620917320

Suárez, H. J. (2006). Pierre Bourdieu y la religión: una introducción necesaria. Relaciones: Estudios de Historia y Sociedad, 27(108), 19-27. Recuperado de https://www.redalyc.org/articulo.oa?id=137/13710802

Turco, D. (2016). Religious forms in secularized society: Three Catholic groups in comparison. Social Compass, 63(4), 513-528. https://doi.org/10.1177/0037768616663986

Vanhoye, A. (1989). El problema bíblico de los carismas. En R. Latourelle (Ed.), Vaticano II: balance y perspectivas. Veinticinco años después (1962-1987) (pp. 295-312). Salamanca: Sígueme.

Vanhoye, A. (2011). I carismi nel Nuovo Testamento. Roma: Gregorian y Biblical Press

Villar, J. R. (1998). El Espíritu Santo, "Principium unitatis Ecclesiae”. Scripta Theologica, 30(3), 831-860. Recuperado de https://hdl.handle.net/10171/13336 